\title{
Multifuncionalidade da palavra eto: implicações para o ensino de russo para estrangeiros
}

\author{
Diego Leite de Oliveira ${ }^{1}$
}

\begin{abstract}
This article aims at presenting an analysis of the different usages of the word eto in Russian, given the complexity and multifunctionality of using this element, which may be classified either as a demonstrative pronoun, functioning as a determiner in a noun phrase, or as discourse particle, presenting several functions, without losing however its deictic character.
\end{abstract}

Keywords: eto; usage; Russian; polissemy; multifunctionality.

Resumo: Este artigo visa a apresentar uma análise dos diferentes usos e caracterizações da palavra eto em língua russa, dada a complexidade e multifuncionalidade de utilização desse elemento, que pode ser caracterizado ora como um pronome demonstrativo, funcionando como determinante de um sintagma nominal, ora como partícula discursiva, apresentando funções diversificadas, sem perder, contudo, seu caráter dêitico.

Palavras-chave: eto; uso; russo; polissemia; multifuncionalidade.

\section{Introdução}

Na linguística de orientação cognitivo-funcional, há larga tradição na análise de estruturas que apresentam formas variadas, utilizadas para expressar o mesmo conteúdo referencial. Nesse caso, algumas abordagens evocam o princípio da não sinonímia, de acordo com o qual, se duas construções são sintaticamente distintas, elas devem ser semântica ou pragmaticamente distintas (Goldberg, 1995). Por outro lado, nas últimas décadas vem aumentando o interesse por unidades linguísticas que apresentam forma única, a qual, por sua vez, pode apresentar significados distintos, a depender do contexto em que é utilizada. Aqui, muita atenção vem sendo dada ao conceito de polissemia e sua distinção em relação ao conceito de homonímia. Independentemente dos caminhos adotados, as conclusões a que chegam os estudiosos têm contribuído para confirmar que o uso das formas linguísticas é motivado e que os elementos que caracterizam tal motivação podem ser tanto de natureza linguística, abrangendo os mais diversos níveis de análise, como extralinguística, envolvendo domínios variados da cognição humana, bem como o contexto pragmático de utilização da língua, o que é

\footnotetext{
${ }^{1}$ Professor de Língua Russa da Universidade Federal do Rio de Janeiro. Doutorando em Linguística pelo Programa de Pós-Graduação em Linguística (UFRJ), tradutor e intérprete. E-mail: diegooliveira@letras.ufrj.br.
} 
possível conferir em Labov (1972), Bybee (2010), Givón (1994), Langacker (2009) e Braga (2009), entre outros.

Observem-se os exemplos (1), (2) e (3), do russo:

(1) Вот если взять несколько последних месяџев / то ваше отношение за это время к правительству изменилось или нет?

Vot iesli vziat nieskol'ko poslednikh miesiatsev / to vache otnochenie za eto vriemia k pravitel'stvu izmenilos ili niet?

(2) Но “Масяня" это всё-таки мультики, которые можно только в сети cмoтреть.

No "Masiania" eto vsio-taki multiki, kotorie mojno tol'ko v seti smotret.

\section{(3) Это она мне говорила, что не глупая...}

Eto ona mnie govorila, tchto nie glupaia...

É possível verificar, a partir dos exemplos acima, que a palavra eto assume funções distintas e apresenta, consequentemente, significados também distintos a depender do contexto no qual se insere. Em (1), funciona como um pronome demonstrativo, determinante de um sintagma nominal; em (2), parece ligar dois elementos - função que, em outras línguas, é geralmente expressa por um verbo cópula; ${ }^{2}$ e, em (3), atua como marcador de foco.

Neste trabalho, estudamos o caráter multifuncional da palavra eto, caracterizando os contextos possíveis de sua utilização, de acordo com o modelo estatístico utilizado pela Sociolinguística Variacionista (Labov, 1972). Além disso, buscamos identificar em que medida uma abordagem linguística à luz dos Modelos Baseados no Uso da Língua (Bybee, 2010; Barlow e Kemmer, 2001; Langacker, 2001 e 2008) pode fornecer contribuições para o ensino de russo como língua estrangeira. $O$ artigo se divide em quatro partes: a primeira constitui esta breve introdução; na segunda, discutimos a forma como as gramáticas tradicionais e os manuais de ensino de língua russa para estrangeiros tratam a palavra eto; em seguida, na terceira parte, apresentamos os resultados de uma análise qualitativa e quantitativa dos contextos em que a palavra

\footnotetext{
${ }^{2}$ A ideia de que eto pode funcionar como partícula de cópula é defendida na linguística de orientação gerativista, como é possível constatar em Geist (2007) e Markman (2008). Há, no entanto, alguns estudos de orientação funcionalista que preferem dar outro tipo de descrição ao fenômeno em questão, como, por exemplo, a possibilidade de eto retomar uma construção de tópico.
} 
eto pode ocorrer; na quarta e última parte, fazemos alguns apontamentos relativos ao ensino de russo como língua estrangeira, considerando as contribuições dos Modelos Baseados no Uso da Língua acima referidos.

\section{O vocábulo eto: visão tradicional}

Não é possível encontrar em manuais, dicionários e gramáticas da língua russa explicações abrangentes, que consigam dar conta da grande quantidade de contextos de uso da forma eto de maneira unificada. Geralmente, tais materiais podem identificar os usos de tal vocábulo, apresentando alguns exemplos oriundos da literatura clássica russa ou inventados pelos próprios gramáticos, mas sem discorrer a respeito de como as formas podem ser de fato empregadas em contextos diversificados de uso corrente da língua.

Atualmente, a forma eto é classificada pelo menos de duas maneiras distintas. Vinogradov (1964), Pulkina \& Zakhava-Nekrasova (1985), Ojegov (2010), Ushakov (2007), Savko (2008), entre outros, fazem a distinção entre o pronome demonstrativo eto e a partícula demonstrativa eto. No primeiro caso, o vocábulo estudado constitui a variante neutra do pronome demonstrativo etot. No segundo caso, a palavra eto é invariável.

Nem sempre os estudiosos de russo concordam com a classificação das funções apresentadas para eto. Em alguns casos, dicionários e gramáticas podem indicar funções relativamente contraditórias no que diz respeito à classificação das ocorrências como pronome e como partícula. Ushakov (2008), por exemplo, abarca, sob o rótulo de pronome, usos em que eto funciona de fato como partícula de focalização, o que não é reconhecido por Ojegov (2010). Wheller e Ubengau (1998), em seu dicionário Oxford russo-inglês, classificam eto sob três rótulos distintos: pronome demonstrativo (variável neutra da forma pronominal etot), pronome demonstrativo invariável e partícula de ênfase, apresentando exemplos de uso e classificações que diferem em comparação ao supracitado Ushakov.

Estudiosos italianos, tais como Ferro (2012), tendem a identificar eto como um caso de homonímia. Ferro (2012) acredita que a multifuncionalidade desse vocábulo se deve ao fato de eto (pronome) e eto (partícula) constituírem, em essência, vocábulos distintos, embora compartilhem a mesma estrutura fonológica. 
Por outro lado, é difícil negar que todas as formas de eto apresentadas em (1), (2) e (3) acima possuem, mesmo que indiretamente, caráter dêitico, ora funcionando de maneira catafórica, ora anafórica. Assim, não se pode afirmar categoricamente que as formas de eto não compartilham entre si funções ou significados. Nesse caso, a afirmação de que eto como pronome e eto como partícula constituem um caso evidente de homonímia pode não ser inteiramente pacífica.

Basta verificar que o dicionário de V. Dahl, do século XIX, não identifica a forma eto como vocábulos distintos. Aqui verificaremos que esse vocábulo era caracterizado como a forma neutra do pronome demonstrativo etot, sendo fornecidos diversos contextos de uso, inclusive empregos nos quais a variável neutra eto poderia funcionar como partícula discursiva. Além disso, Dahl relaciona o pronome demonstrativo às formas dialetais evtot e entot, que deram origem ao vocábulo vot. Para Ivanov (1990), a forma pronominal etot e suas variantes eta/eto/eti surgiram a partir da fusão do pronome tot/ta/to/te com a partícula "e". Essa partícula, num momento inicial, ocorria separadamente do pronome. Com o uso de tot em contextos preposicionados, a preposição precedia a partícula e se repetia antecedendo o pronome (въ е въ то, на е на томь, съ е съ тъмь). Com о passar do tempo a preposição entre a partícula "e" е o pronome to desapareceu, permitindo que a partícula se unisse ao pronome, formando o vocábulo eto e fixando significado distinto de sua forma inicial "to". Uso semelhante levou à criação das formas efto, ento, esto, como descrito por Dahl.

As evidências elencadas acima indicam que as pesquisas referentes ao emprego da palavra eto carecem de estudos empíricos e experimentos que analisem um pouco mais do que meia dúzia de instâncias de ocorrência do elemento em questão. Além disso, devem-se analisar os usos de tal vocábulo, tendo-se como referência arcabouço diferenciado de contextos nos quais é possível sua ocorrência, nos mais distintos gêneros textuais e não apenas naqueles tidos como ambientes de manifestação canônica da língua. A próxima seção deste artigo se propõe a esse tipo de análise, ainda que se encontre em um estágio preliminar de desenvolvimento da pesquisa.

\section{Contextos de uso de eto: uma análise empírica}

Para que se tenha clareza sobre os possíveis usos do vocábulo eto em russo, recorremos a dois tipos de análise (até este momento, num estágio bem inicial da pesquisa) que se complementam. Inicialmente, observamos o comportamento das 
diversas formas de eto na fala, buscando identificá-las, de acordo com a função que apresentavam no contexto de ocorrência no qual foram coletadas. Em seguida, demos a essas ocorrências o devido tratamento estatístico.

O primeiro tipo de análise nos levou a considerar as formas de eto como pronome demonstrativo e como partícula demonstrativa, de acordo com o padrão apresentado abaixo:

\begin{tabular}{|c|c|c|}
\hline I. & $\begin{array}{l}\text { Pronome demonstrativo } \\
\text { como determinante de } \\
\text { um sintagma nominal }\end{array}$ & $\begin{array}{l}\text { (4) Да, это место прямо намекало на близкие } \\
\text { неприятности. } \\
\text { Da, eto miesto priamo namekalo na blizkie } \\
\text { niepriiatnosti. }\end{array}$ \\
\hline II. & $\begin{array}{l}\text { Pronome demonstrativo } \\
\text { com função anafórica }\end{array}$ & $\begin{array}{l}\text { (5) Проблемьл сбыта продукции, диспаритета иеен, } \\
\text { налогового бремени - основные, главные, но на } \\
\text { уровне колхоза их не решишь, это я знаю } \\
\text { точно. } \\
\text { Probliemi sbyta produktsii, disparitieta tsen, } \\
\text { nagolovogo briemeni-osnovnyie, glavnyie, no na } \\
\text { urovnie kolkhoza ikh nie riechich', eto ia znaiu } \\
\text { totchno. }\end{array}$ \\
\hline III. & $\begin{array}{l}\text { Partícula demonstrativa } \\
\text { com função de foco }\end{array}$ & $\begin{array}{l}\text { (6) Мой сын тоже иногда бывает с утра ноет, } \\
\text { что он не хочет кушать, но я ему уже давно } \\
\text { объяснила, что это он проснувшись не хочет } \\
\text { кушать, а через час очень даже захочет } \\
\text { Mоi syn toje inogda byvaiet s utra noiet, tchto on } \\
\text { nie khotchet kuchat', no ia iemu uje davno } \\
\text { ob',iasnila, tchto on prosnuvchis nie khotchet } \\
\text { kuchat, a tcherez,tchas otchen daje zakhotchet. }\end{array}$ \\
\hline IV. & $\begin{array}{l}\text { Partícula demonstrativa } \\
\text { com função de cópula }\end{array}$ & $\begin{array}{l}\text { (7) Членство в НАТО / это в принщ̧ипе для них } \\
\text { хорошие позищии. }\end{array}$ \\
\hline
\end{tabular}




\begin{tabular}{|c|c|c|}
\hline & & $\begin{array}{l}\text { Tchlienstvo } v \text { NATO / eto } v \text { printsipie dlia nikh } \\
\text { khorochie positsii. }\end{array}$ \\
\hline V. & $\begin{array}{l}\text { Partícula demonstrativa } \\
\text { de interrogação }\end{array}$ & $\begin{array}{l}\text { (8) A что это вы тут делаете? } \\
\text { A tchto eto vy tut dielaietie? }\end{array}$ \\
\hline VI. & $\begin{array}{l}\text { Partícula demonstrativa } \\
\text { apresentativa }\end{array}$ & $\begin{array}{l}\text { (9) Это тот / который держит камеру в руках и } \\
\text { всех вас сейчас фиксирует. } \\
\text { Eto tot kotoryi dierjit kamieru v rukakh i vsiekh vas } \\
\text { sieitchas fiksiruiet. }\end{array}$ \\
\hline
\end{tabular}

Em seguida, tais padrões foram analisados levando-se em consideração os fatores relacionados abaixo:

a) Concordância: algumas funções de eto requerem concordância de número, pessoa e caso obrigatória com o referente, ao passo que outras funções dispensam obrigatoriamente a concordância. Tal fator é de vital importância para o estabelecimento da diferenciação entre partícula e pronome. Além disso, pronomes assumem função sintática nas sentenças em que ocorrem, partículas geralmente não possuem função sintática definida. Atuam como marcadores do discurso, auxiliando na ligação de unidades, tal como atuam algumas conjunções e preposições.

b) Posição na sentença: a depender da função da forma eto no contexto em que ocorre, ela pode aparecer em posição inicial, medial ou final. Em algumas funções, a posição pode ser irrelevante. No entanto, no decorrer da pesquisa, algumas funções da forma eto demonstraram sensibilidade ao fator posição, como será visto mais adiante, na parte de resultados.

Para realizar a análise quantitativa, foram selecionadas 100 ocorrências de eto aleatoriamente, a partir do Natsionalniy Korpus Russkogo Iazyka e, após a análise qualitativa acima referida, que atribuiu um código específico para cada fator analisado, tais ocorrências foram processadas pelo programa estatístico GOLDVARB X, que fez o cruzamento entre os fatores elencados.

De acordo com o processamento do programa, foi possível chegar aos resultados apresentados a seguir: 


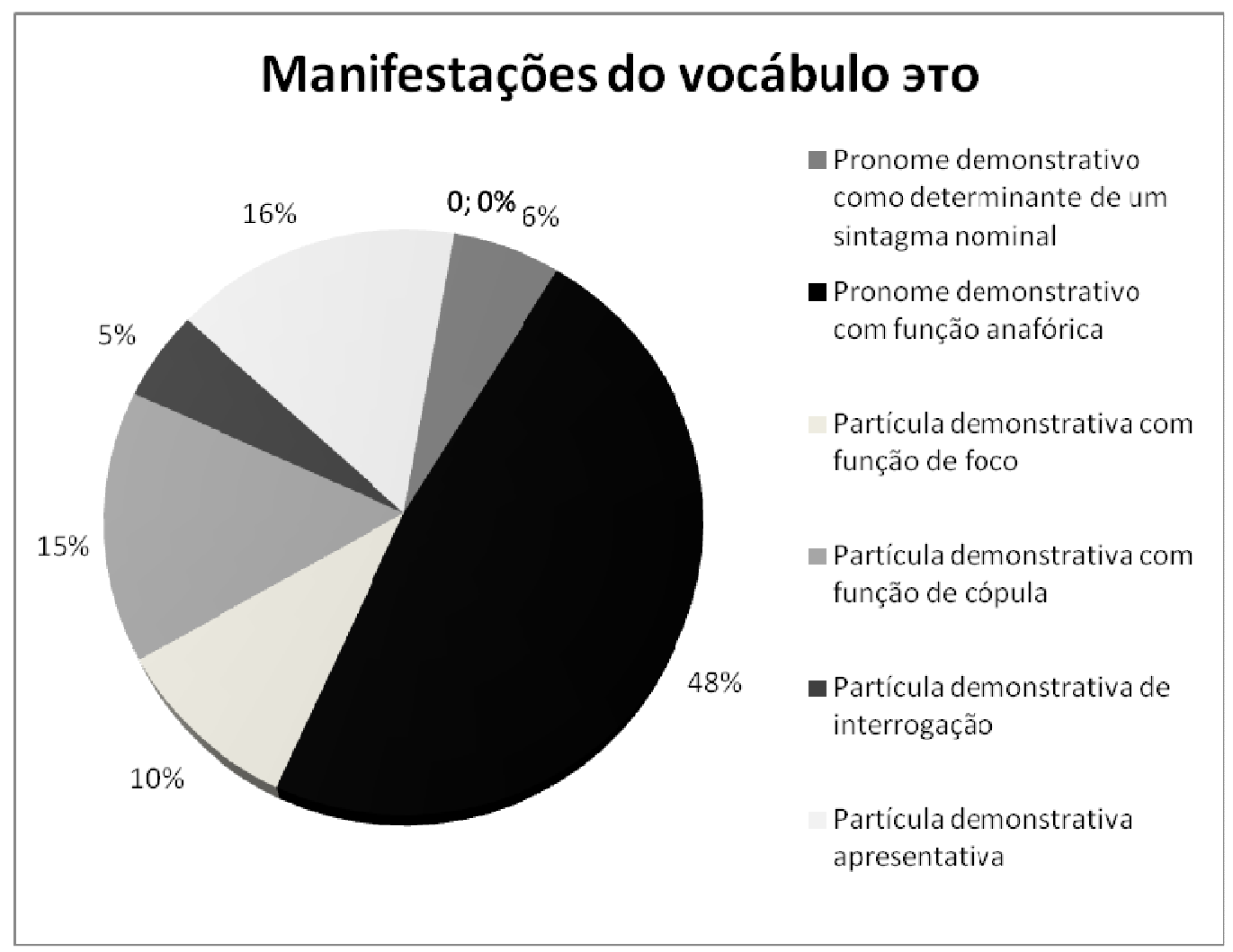

Figura 1. Gráfico de ocorrência do vocábulo eto na amostra selecionada

De acordo com o gráfico apresentado acima, na amostra selecionada para análise, a maior parte das ocorrências do vocábulo eto se dá como pronome demonstrativo com função anafórica. Tal resultado parece coerente, tendo em vista a função dêitica do pronome eto, além de sua função textual coesiva. O pronome demonstrativo com função anafórica funciona como substituto de vocábulos, expressões ou até mesmo orações que já foram mencionadas no cotexto anterior, evitando que eles sejam repetidos várias vezes num mesmo texto.

Além disso, $30 \%$ das ocorrências são distribuídas entre as funções de cópula e apresentativa. No que diz respeito à cópula, tais tipos de ocorrência merecem estudo específico, em razão da possibilidade de tais ocorrências serem interpretadas também como dêiticos anafóricos numa construção de tópico, como salienta Grenoble (1998), embora larga tradição de estudos gerativistas busque defender a atuação de eto como partícula de ligação.

As demais ocorrências se dividem entre a forma tradicional como pronome demonstrativo determinante de um sintagma nominal, eto como marcador de foco e eto como partícula que acompanha orações interrogativas, que juntas correspondem a aproximadamente $20 \%$ de todas as ocorrências. 
Para que se possa ter mais clareza sobre a real frequência do vocábulo eto nas formas investigadas nesta pesquisa, faz-se necessário analisar maior quantidade de dados, o que será feito em momento posterior. No entanto, os cruzamentos entre fatores, realizados pelo programa GOLDVARB $\mathrm{X}$ indicam tendências interessantes, apresentadas a partir dos gráficos apresentados abaixo:

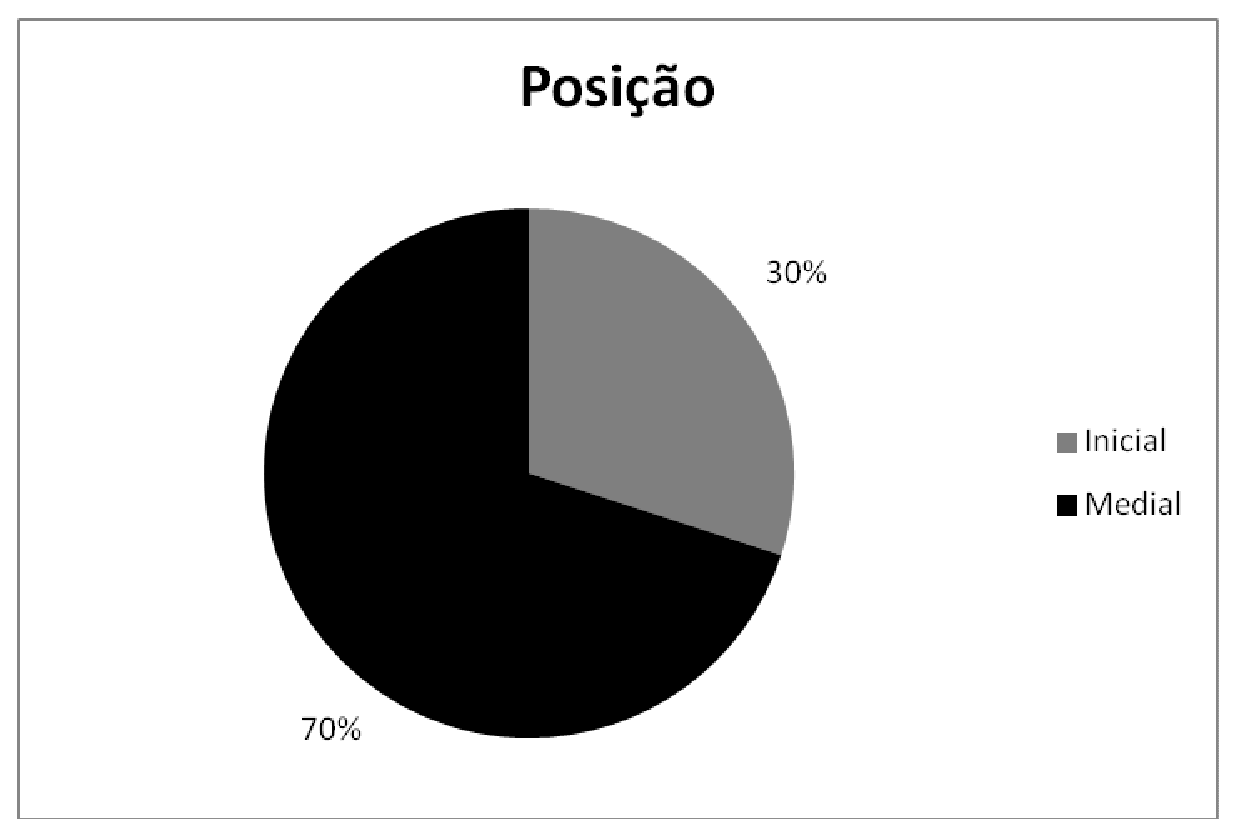

Figura 2. Posição de eto na oração

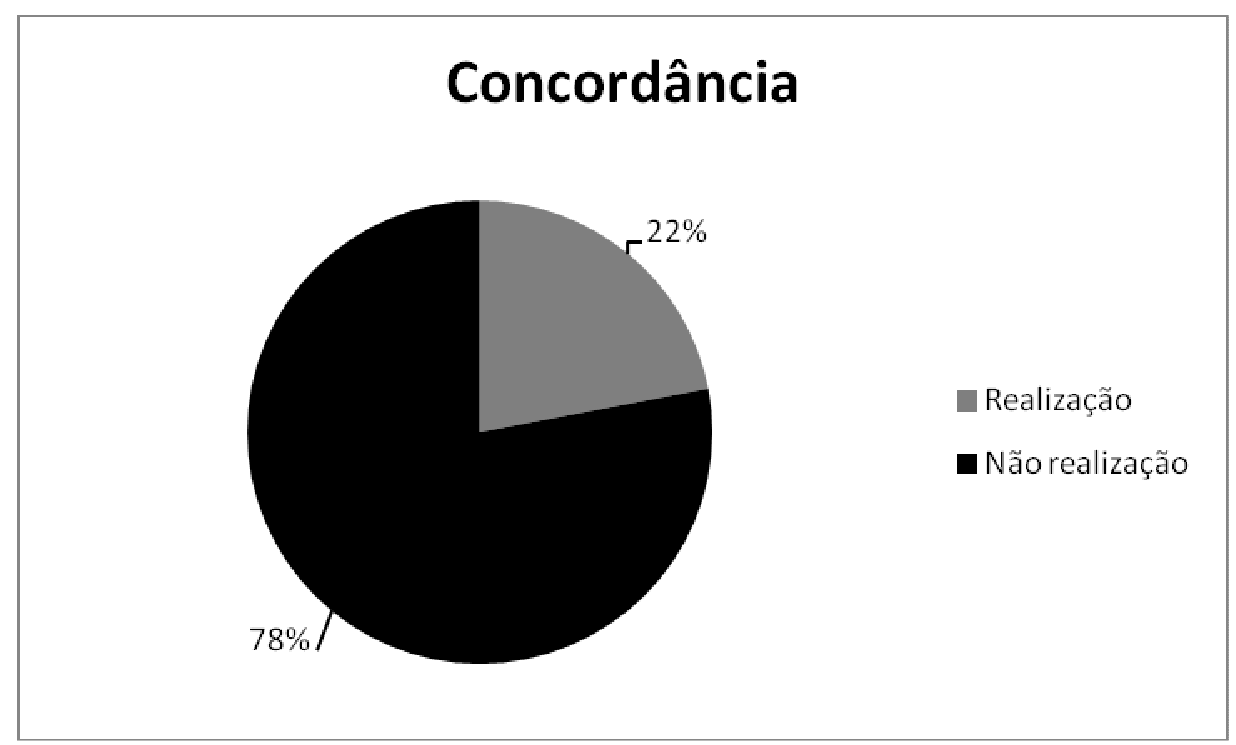

Figura 3. Realização da concordância de eto com o referente 
Os gráficos acima apresentados se referem à posição em que eto ocorre na sentença, assim como à realização ou não da concordância com o referente. Cabe ressaltar que na amostra selecionada para a pesquisa não foram encontradas ocorrências de eto em posição final na oração, o que não quer dizer que eto não possa ocorrer em tais contextos, já que a quantidade de dados analisados é ainda relativamente pequena. No entanto, o pronome demonstrativo com função anafórica se refere justamente a elementos já mencionados em contexto anterior, de maneira que, se levarmos em consideração que a ordem dos elementos é influenciada pelo seu status informacional, tal como afirma Oliveira (2013), ficará claro que a ocorrência de eto será muito reduzida, mesmo em um conjunto de dados mais significativo.

De acordo com os gráficos acima, é possível depreender que a maior parte dos dados indica a ocorrência de eto em posição medial (70\%), bem como a não realização de concordância com o elemento ao qual eto se refere. Tais dados nos levam a concluir que o vocábulo eto em russo, como pronome demonstrativo com função anafórica, pode não concordar exatamente com o seu referente. Isso se deve ao fato de muitas vezes eto se referir a uma situação expressa por meio de um verbo ou de uma construção inteira, daí a obrigatoriedade de ser produzido na forma neutra.

Os resultados acima apresentados parecem indicar que não há uma linha bem delimitada que estabeleça claramente que eto como pronome e eto como partícula constituam um caso prototípico de homonímia.

Dessa forma, torna-se difícil explicar a um aluno que as duas formas de eto supracitadas constituem realmente dois vocábulos distintos, com significados completamente estanques. Assim, cabe salientar, na próxima seção, de que maneira abordar o tema em questão, valendo-se das abordagens linguísticas baseadas no uso da língua, em especial as contribuições fornecidas pela Gramática de Construções.

\section{Eto e implicações sobre o ensino de russo para estrangeiros}

Ao analisar construtos que apresentam a mesma estrutura fonológica e, muitas vezes, a mesma grafia, o aprendiz de russo depara com obstáculos cuja transposição pode não ser tão pacífica. É o caso do estudo da forma eto, como salientado neste artigo.

Ao iniciar os estudos de russo, um estudante estrangeiro, falante nativo de língua portuguesa, geralmente recebe a informação de que a palavra eto é um pronome demonstrativo. No entanto, desde o início o estudante se defronta com os mais diversos 
usos de tal vocábulo, em contextos variados, e, por fim, passa a ter dúvidas sobre a sua real utilização, pois percebe que o uso da palavra em questão vai muito além de seu emprego como pronome demonstrativo, pelo menos em relação à maneira como tal pronome é utilizado em língua portuguesa.

Como já visto, eto pode, a depender do contexto, atuar como pronome demonstrativo, concordando, nesse caso, em gênero, número e caso com o elemento a que se refere; como partícula demonstrativa, na qual assume caráter invariável e função catafórica; ou, ainda, como elemento de cópula, ligando um sujeito a um predicativo. Atualmente é possível verificar que dicionários e gramáticas tradicionais de ensino de russo, seja como língua materna, seja como L2, classificam eto no âmbito de duas categorias distintas: pronome demonstrativo e partícula demonstrativa. Cabe salientar que todos os materiais mencionados valorizam a forma de uso canonizada da língua, de maneira que os exemplos apresentados para elucidar as explicações provêm da literatura russa clássica, sem haver qualquer tipo de espaço dado ao uso corrente da língua, seja em sua modalidade escrita, seja em sua modalidade falada - e isso, no caso do ensino de língua russa para estrangeiros, pode ser um tanto controverso.

Nesse sentido, Ferro (2012) e Remonato (2005) demonstram que estudantes de russo como língua estrangeira, especificamente os italianos, no caso das autoras citadas, tendem a realizar a concordância de eto com o item ao qual eto se refere, mesmo que sua função não seja a de pronome demonstrativo, concordância que não é aceitável em língua russa.

Dessa forma, Ferro (2012) demonstra que desde o início dos estudos os alunos precisam receber uma descrição contrastiva de eto como pronome e como partícula, sendo, para isso, necessária a introdução do conceito de homonímia. Para Ferro, o fato de as formas de eto serem homônimas deve ser considerado de vital importância no ensino de russo para estrangeiros.

No entanto, como apontam os resultados apresentados neste artigo, as manifestações de eto podem não constituir casos categóricos de homonímia. Assim, explicar as diversas funções de eto como homônimas pode não ser tão produtivo quando se trata do ensino de russo para estrangeiros.

Particularmente acreditamos que o conceito de homonímia não deve ser utilizado em sala de aula como recurso metodológico para ensino das diferenças entre as formas de eto. Acreditamos que o ensino de língua deve-se pautar nas mais diversas formas de uso, levando-se em consideração os variados gêneros textuais em que a 
língua se manifesta. Dessa forma, para o ensino, mais importante que o conceito de homonímia talvez seja o conceito de construção.

$\mathrm{Na}$ literatura linguística, em especial nos Modelos Baseados no Uso, o conceito de construção, qual seja o de pareamentos de forma e significado - em que significado inclui também aspectos pragmáticos, de acordo com Goldberg (1995), Bybee (2010) e Langacker (2008) -, tem sido vital na descrição e explicação dos diversos usos da língua. Construções podem ou não apresentar posições esquemáticas (fixas). No caso dos usos de eto, é possível considerar construções distintas, como exemplificado abaixo:

i. ETO [adjetivo] substantivo (inserida em uma construção maior, assumindo funções sintáticas variadas a depender do contexto);

ii. [adjetivo] substantivo ETO [adjetivo][substantivo] (com função identificacional/cópula);

iii.ETO elemento focalizado - verbo (com função de focalização);

iv. Pronome interrogativo ETO oração (como focalizador de uma pergunta);

v. ETO elemento apresentado.

Uma vez estabelecidas as construções possíveis de eto no discurso oral, deve-se ter clareza a respeito do momento em que se vai apresentá-las ao estudante.

Como os modelos baseados no uso salientam a importância dos eventos de uso na emergência da linguagem, considerar situações reais de uso no ensino de língua estrangeira torna-se fundamental. Deve-se ter a consciência dos contextos de uso da palavra eto e apresentar os tipos de construção de acordo com as necessidades comunicativas correspondentes aos estágios de aprendizado do aluno. À medida que ele vai sentindo necessidade de aprimorar suas capacidades discursivas, deverão ser introduzidas novas construções. Aproximar a gramática do seu uso e reconhecer que ela atende às finalidades sociocomunicativas dos falantes de uma língua pode constituir fator extremamente relevante no ensino de línguas, em todos os níveis da gramática. $\mathrm{Na}$ verdade, nos modelos baseados no uso da língua, tal perspectiva se torna essencial à efetiva proficiência de língua. 


\section{Referências bibliográficas}

Barlow, M. \& Kemmer, S. (eds.). Usage-Based Models of Language. Chicago: University of Chicago Press, 2000.

Bybee, Joan. "From Usage to Grammar: The Mind's Response to Repetition". Language, 82(4) 2006, 711-733.

- Language, Usage and Cognition. Cambridge: Cambridge University

Press, 2010.

Dahl, V. Tolkovyi Slovar' Jivogo Velikorusskogo Iazyka. Moskva: Nauka, 1982.

Dolenga, M. A Língua Russa - Gramática Elementar. Porto Alegre: Globo, 1961.

Golberg, A. E. A Construction Grammar Approach to Argument Structure. Chicago: University of Chicago Press, 1995.

Halliday, M. K. A. "Linguistics and the Teaching of English". In: Briton, J. N. (ed.). Talking and Writing: A Handbook for English Teachers. London: Methuen, 1967.

Langacker, R. Cognitive Grammar: A Basic Introduction. New York: Oxford University Press, 2008.

. “A Dynamic Usage Based Model”. In Barlow, M. \& Kemmer, S. Usage-

Based Models of Language. Chicago: University of Chicago Press, 2000, p. 1-63.

Markman, V. G. "Pronomial Copula Constructions Are What? Reduced Specificational Pseudo-Clefts!". In: Proceedings of the 26th West Coast Conference on Formal Linguistics. Chang, C. \& Haynie, H. J. (eds.). Somerville, MA: Cascadilla Proceedings Project, 2008, p. 366-374.

Ojegov, S. I. Slovar' Russkogo Iazyka. Moskva: Oniks, 2010.

Pulkina, I. \& Zakharova-Nekrasova, E. Grammatika Russkogo Iazyka dlya Inostrantsev. Moskva: RusskiiIazyk, 1996.

Remonato, I. Considerazioni introduttive a una caratterizzazione delle particelle enfatiche in russo. eSamizdat (III) 1 286, 2003.

Savko, I. E. Gramatica Russkogolazyka. Otfonetiki do Teksta. Moskva: RusskiIazyk, 2008.

Ushakov, D. N. Bol'choi Tolkovyi Slovar' Sovremennogo Russkogo Iazyka. Moskva: Alta-print, 2007.

Vinogradov, V. V. Russkiilazyk. Gramatitcheskoieutchenie o Slovie. Moskva: Udpedgiz, 1947. 